\title{
Finite Element Analysis of the Bending Performance Influencing Factors of GFRP Reinforced Concrete Beams
}

\author{
Abuobieda Alamin Ahmed ALMANSOOR \\ Hubei Key Laboratory of Roadway Bridge and Structure \\ Engineering \\ Wuhan University of Technology \\ Wuhan, China \\ e-mail:abuo_ahmed2001@yahoo.com
}

\author{
Jianwei TU \\ Hubei Key Laboratory of Roadway Bridge and Structure \\ Engineering \\ Wuhan University of Technology \\ Wuhan, China \\ e-mail:Waider1@163.com
}

\begin{abstract}
Glass fiber reinforced polymers (GFRP) bars are non corrosion materials, their tensile modulus relatively are lower compared to steel reinforcement. A total of three beam specimens (GB1 GB3) were simulated under four-point bending. The main parameter's studies were the amount of GFRP reinforcement ratio, concrete strength, concrete cover thickness and the height of beam cross-section. To study the influence of these parameters on the flexural behavior of GFRPs concrete beams, ABAQUS Finite-element software was used. The results showed that; there are clear improving of bearing capacity when the reinforcement ratio and height cross-sections of the beam were increased, but increase of concrete strength lead to increases as the bearing capacity, but this increased is limited by concrete compressive failure strain of reinforced concrete beams, while increasing the concrete cover thickness, lead to a negative efficient of GFRP reinforced concrete bearing capacity.
\end{abstract}

Keywords-ABAQUS; GFRP reinforcement bars; reinforcement ratio; concrete cover thickness; finite element analysis

\section{INTRODUCTION}

Fiber-reinforced-reinforced polymers (FRP) term indicated to a group of materials consisting of synthetic fibers or organic impacted in a matrix resin [1].

FRP has become an alternative material used instead of steel-reinforced concrete structures when the situation of RC member requires durability under the aggressive environmental conditions [2].Their advantage properties are high-tensile strength and excellent insulating during the construction process [3].

There are three most common types of FRPs available in the market are; Carbon fibers (CFRP), Glass fibers (GFRP) and Aramid fibers (AFRP) [1, 4-6]. Under the tension test up to failure, GFRP bars have a linear stress-strain behavior. However, their elastic modulus is less than steel bars, and they have not ductility [5].

The bending behavior of GFRP concrete beams investigated, by the numbers of studies. Theriault and

Benmokrane are studies the effect of concrete strength and GFRP longitudinal ratio on the bending behavior of GFRP concrete beams. They concluded that ultimate moment capacity of concrete beam increases as concrete strength and reinforcement ratio increases [1] Wegian and
Abdullah [7], were conducted an analysis of FRP tensile reinforcement ratio, concrete strength, etc., to study their influence to FRP Reinforced concrete flexural performance. Li Bao Lei [8], conducted a total of seven simply supported beam specimens with different types of FRP (GFRP\&CFRP). The main parameters were considered are; concrete compressive strength, the amount of FRP reinforcement ratios, concrete cover thickness and the beam depth-toheights ratio. They conclude that; increasing of GFRP longitudinal bars ratio and beam depth-to-high ratio led to the increase the load carrying capacity, but increases of concrete strength have been small affective and increased of concrete cover thickness will be a negative efficient to the flexural performance of FRP reinforced beam, that is because FRP it has a good advantage of corrosion resistance property, then no need to increasing the concrete cover thickness [8].

In last decades, the development of Finite element (FE) analysis has increased with increases the knowledge and capabilities of computer software and hardware. Commercial finite-ele ment packages (ABAQUS, ATHENA, DIANA, etc.) now are provided a large powerful and many analytical tools for analys is of RC structures [9].

In this article, used ABAQUS finite-element software to analytical a flexural property of GFRP reinforced concrete beams, at the same time study analysis for some factors; reinforcement ration, concrete strength, concrete cover thickness and height of the beam depth, which are affect to FRP fle xural properties.

\section{THE BEAM MODEL}

The analytical model program consisted of investigating the effects of varying reinforcing ratio, concrete strength, height variable of the beam and concrete cover thickness to flexural capacity of GFRP RC beams. The specimen consisted of three GFRP RC beams (GB1, GB2 and GB3). The total length of each beam was $1900 \mathrm{~mm}$, with rectangular cross-section $250 \mathrm{~mm} \times 180 \mathrm{~mm}$. The specimens were subjected to two concentrated loads with $600 \mathrm{~mm}$ distance from each other, with $1800 \mathrm{~mm}$ total span and $600 \mathrm{~mm}$ shear span Fig.1. $8 \mathrm{~mm}$ diameters of Steel stirrups at $100 \mathrm{~mm}$ spacing for all the beams in the shear span to avoid shear failure were used. No stirrups were provided in the pure bending area. Longitudinal reinforcement bars at the beam 
top were reinforced with $14 \mathrm{~mm}$ diameter of steel reinforced to hold stirrups in place in the shear span zone. Three different amounts of GFRP reinforcements $(2 \varnothing 9.5,3 \varnothing 9.5$ and 4Ø9.5), three different concrete strengths (30, 35 and $45 \mathrm{Mpa}$ ), three different amounts of concrete cover thickness $(25,30$ and $35 \mathrm{~mm})$ and three different variables of the beam heights $(250,300$ and $350 \mathrm{~mm})$ were used in this analytical. Table 1, 2 and 3 shown the material properties of concrete ,steel and GFRP bars respectively [8].

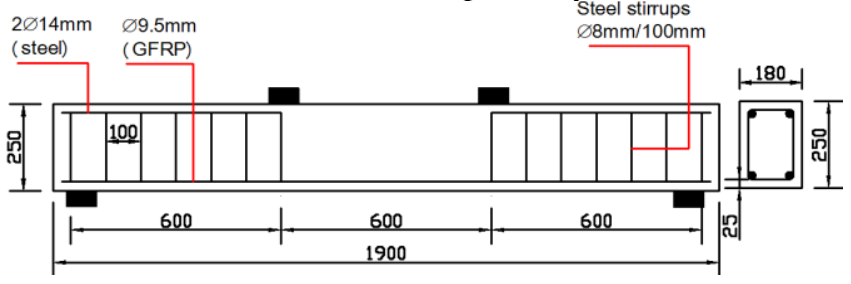

Figure 1. Geometric and reinforcement details (all dimension in $\mathrm{mm}$ )

\section{METhODOLOGY}

After the text edit has been completed, originally, nonlinear of reinforced concrete structures is basically divided into three types [10]; material nonlinearity, geometric nonlinearity and boundary conditions nonlinearity. Material nonlinearity not only takes into consideration the elastic properties of the linear period, but also considers that the nonlinear period of its plastic properties when we analyze the mechanical properties of the concrete and reinforcement. In ABAQUS, we achieved the nonlinear characteristics of the material by determination of steel and concrete constitutive model. In elastic stage should enter the elastic modulus and Poisson's ratio for two materials, while the definition of the plastic stage is different. In this stage, should enter the plastic stage data of stress-strain relationship. However, three different models can be used in concrete plastic phase [11]; concrete damaged plasticity, concrete smeared cracking, and cracking model for concrete of ABAQUS/Explicit. There are some advantages of the Plasticity model of concrete: it can be used in the; dynamic loading, individual load and cyclic loading. The change of boundary conditions (including the contact between the members) in the analysis process will produce boundary nonlinear problems. In ABAQUS, the frictional contact between concrete and reinforcement usually achieved by embedded command. Reinforced ele ment is embedded in concrete element by using embedded technology [12] geometric nonlinearity occurs in the case of the size of the displacement affect the structural response. It only needs to add NLGEOM parameters to STEP options. Generally, in non-linear static analys is NLGEOM parameters it does not required to selecting in order to avoid the tedious amount of computation. Used C3D8R for concrete element and T3D2 for reinforcement element. Used embedded command to make a good bond between concrete and reinforcement. There are two steel blocks were putted on the two loading and supports positions in order to avoid the concentration stress in these positions when we apply the load Fig.2.

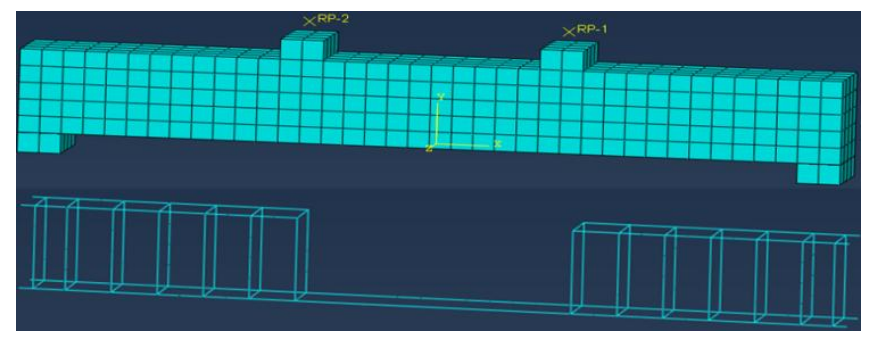

Figure 2. Concrete and reinforcement element

TABLE I. MATERIAL PROPERTIES OF CONCRETE

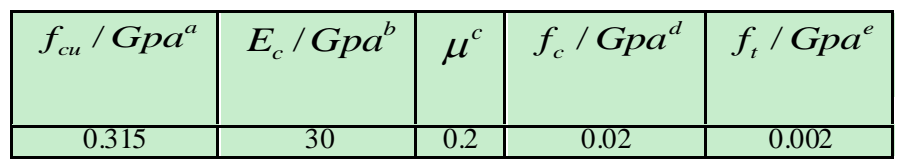

a. Axial Compressive Strength of Concrete. b. Concrete Elastic modulus. c. Poisson's ratio. d. Concrete Compressive strength. e. Concrete tensile strength.

TABLE II.MATERIAL PROPERTIES OF STEEL REINFORCEMENT

\begin{tabular}{|c|c|c|c|}
\hline Types of steel & $\boldsymbol{\mu}$ & $E_{s} / \mathrm{Gpa}^{f}$ & $f_{y} / \mathrm{Gpa}^{g}$ \\
\hline Compression steel & 0.25 & 200 & 0.380 \\
\hline Stirrups steel & 0.25 & 200 & 0.308 \\
\hline Steel (block)plate & 0.30 & 200 & 0.400 \\
\hline
\end{tabular}

TABLE III. MATERIAL PROPERTIES OF GFRP REINFORCEMENT

\begin{tabular}{|c|c|c|c|c|c|}
\hline $\begin{array}{c}\text { Beams } \\
\text { type }\end{array}$ & $\begin{array}{c}\text { Bars } \\
\text { number }\end{array}$ & $\rho \%^{h}$ & $\mu$ & $E_{f} / G p a^{i}$ & $f_{f} / G p a^{j}$ \\
\hline$B 1$ & 2 & 0.315 & 0.3 & 40 & 0.61 \\
\hline $\boldsymbol{B} 2$ & 3 & 0.473 & 0.3 & 40 & 0.61 \\
\hline $\boldsymbol{B 3}$ & 4 & 0.630 & 0.3 & 40 & 0.61 \\
\hline
\end{tabular}

\section{RESULT ANALYSIS}

The load to midspan deflection curves for all of the GFRP reinforced concrete beams are presented in Fig.3-6. The loads to midspan deflection curves were bilinear for all of specimens. The first part of the curve up to cracking represents the behavior of the un-cracked beams. The second part represents the behavior of the cracked beams with reduced stiffness, while the third part represented to the failure point.

\section{A. Effect of Reinforcement Ratio}

The influence of the amount of longitudinal GFRP bars was examined by comparing analysis results of specimens (GB1, GB2 and GB3) Fig.3. As expected, since specimen GB3 had higher reinforcement ratio, it achieved higher load carrying capacity and more favorable deformability than that of specimen GB1. The flexural strength of specimen GB3 was $26.62 \mathrm{kN} \mathrm{m}$, that is, approximately $66 \%$ greater than GB1specimen. Furthermore, with increasing of GFRP reinforcement ratio from $3.15 \%$ (GB1) to $6.30 \%$ (GB3), led to increased in the ultimate capacity from $58 \mathrm{kN}$ to $93.16 \mathrm{kN}$. agreement with Xian Li [13]. 


\section{B. Effect of Concrete Strength}

The impact of the concrete compressive strength on flexural behavior can be evaluated by comparing the capacity of specimens GB1 with different amount of concrete strength and identical amount of longitudinal GFRP bars Fig.4. Specimen GB1-45Mpa constructed from higher strength concrete gained the flexural strength comparable to that of specimen GB1-30Mpa, indicating that use of higher strength concrete has a little effect on improving the load carrying capacity of FRP-RC beams. This may be attributed to the slight reduction of the ultimate strain of concrete with the increase of strength. Generally, can be say that; increasing the concrete strength led to increases the flexural capacity of FRP reinforced concrete beam, but this increased is limit by concrete compressive failure strain of GFRP reinforced concrete beams. This conclude is agreement with Theriault and Ben mokrane [1].

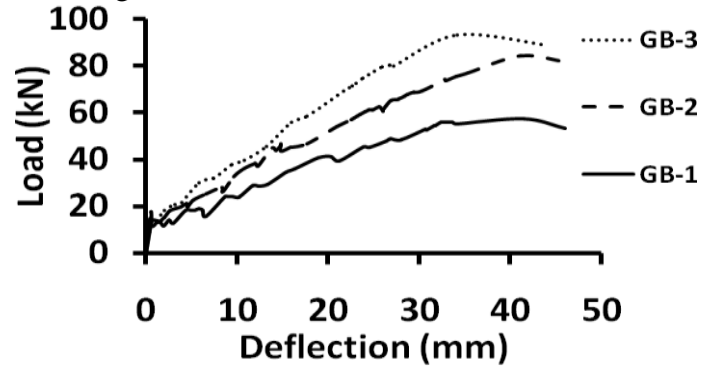

Figure 3. GFRP Load-Deflection curves with different amounts of reinforcement ratios

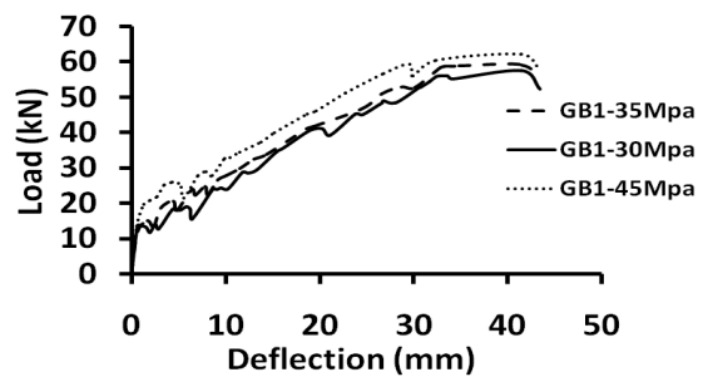

Figure 4. GB-1 Load-Deflection curves with different amounts of concrete strength

\section{Effect of Cross-section Height of the Beam}

The impact of the height of the beam cross-sections on flexural behavior can be evaluated by comparing the capacity of specimens GB1 with different a mount of height beam cross-section and identical amount of longitudinal GFRP bars Fig.6. In this figure only considered the height of beam cross-section while; concrete strength, concrete cover thickness and reinforcement ratio are constants. The heights cross-sections which were taken respectively are; 250,300 and $350(\mathrm{~mm})$. In this figure can be observed that; the height of beam cross-section had a large influence to the flexural behavior of FRP reinforced concrete beam than concrete strength. The fle xural capacity of specimen (GB1$350 * 180 \mathrm{~mm}$ ) was $25.5 \mathrm{kN}$ m that it's approximately $47.4 \%$ greater than that of specimen (GB1-200*180mm). Furthermore, with increasing ratio of the height cross- section of GFRP beam $(200 * 180) \mathrm{mm}$ to $(350 * 180 \mathrm{~mm})$, led to increased in the ultimate capacity from $57.57 \mathrm{kN}$ to 84.97 $\mathrm{kN}$ respectively. This indicated that; increasing of the beam height cross-section led to increase of; beam stiffness, moment of inertia, ultimate load and reduced of deflection. This concludes also agreement with Li BaoLei [8].

\section{Effect of Concrete Cover Thickness}

The impact of the concrete cover thickness on flexural behavior can be evaluated by comparing the capacity of specimens GB1 with different amount of concrete cover thickness and identical amount of longitudinal GFRP bars Fig.5. From this figure can be observed that, before cracking occurred, the affective of concrete cover thickness to the bearing capacity of concrete beam reinforced with GFRP bars is a little. With increasing the load, the slope of curve was increases fester. With the continuously, the ultimate capacity of beam which has a large concrete cover thickness (GB1-35) it was decreased. Indicating that; increasing of concrete cover thickness will be negative affected to flexural capacity of GFRP reinforced concrete beam. However because of FRP bars have a good advantage of corrosion-resistant property so, no need to consider of increasing the concrete cover thickness factor to prevent corrosion of FRP bars, only need this to meet the minimum requirements. This concludes is agreement with Li BaoLei et al [8].

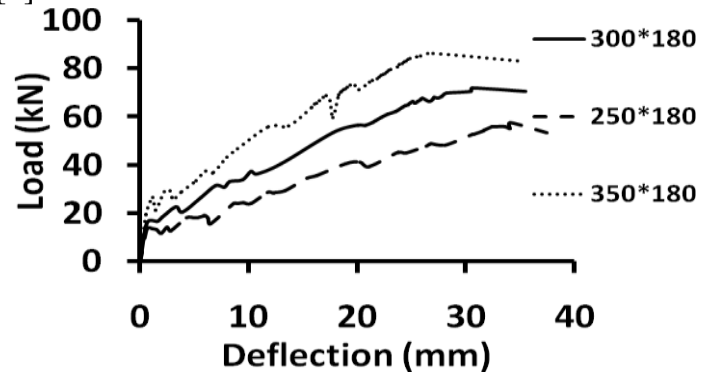

Figure 5. GB-1 Load-Deflection curves with different amounts of height beam cross-sections

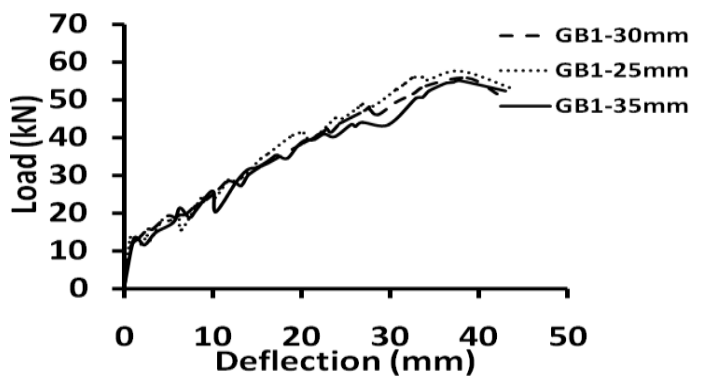

Figure 6. GB-1 Load-Deflection curves with different amounts of concrete strength

\section{CONCLUSION}

- All the specimens behave in a linear until cracked occurred and due to the lack of plasticity in the reinforcement, almost linearly between cracking and failure with a greatly reduced slope. However, failure took a place at relatively large displacements. Increasing the reinforcement ratio from $3.15 \%$ to 
$6.30 \%$, tends to increase the ultimate capacity from $58 \mathrm{kN}$ to $93.16 \mathrm{kN}$ respectively figure 3 .

- Increasing the height of beam cross-section, lead to a large influence on stiffness of the beam specimens and therefore the bearing capacity figure 6 .

- Increasing the concrete strength led to increases of ultimate capacities of the beams specimens but this increased is limit by concrete compressive failure strain of rein forced concrete beams figure 4 .

- Increasing the concrete cover thickness led to a negative efficient of the bearing capacity of GFRP concrete beam, that is because, ultimate capacities were decreased with increased of concrete coverthickness. This indicates that; a good corrosion resistance property of GFRP, then no need to improve of GFRP beam capacity by increases of concrete cover-thickness figure 5.

\section{ACKNOWLEDGMENT}

A. Almansoor gratefully acknowledges the Chinese Scholarship Council (CSC) for funding this $\mathrm{PhD}$ research.

Also he would like to thank Wuhan University of Technology for providing a lot of information's facilities to conduct this article.

\section{REFERENCES}

[1] R. Masmoudi, M. Theriault, and B. Benmokrane, "Flexural behavior of concrete beams reinforced with deformed fiber reinforced plastic reinforcing rods," Structural Journal, vol. 95, pp. 665-676, 1998.

[2] J. Newman and D. Svecova, "Reinforcing Concrete Structures with Fiber Reinforced Polymers: design manual no. 3," ed: Canada: ISIS Canada Corporation, 2007.
[3] M. S. Asslanova, "Glass fibers," Elsevier, vol. 41, 1985.

[4] H. Saadatmanesh, "Fiber composites for new and existing structures," Structural Journal, vol. 91, pp. 346-354, 1994.

[5] R. Fico, "Limit states design of concrete structures reinforced with FRP bars," Università degli Studi di Napoli Federico II, 2008.

[6] A. Machida and K. Maruyama, "Design code development for fibre - reinforced polymer structures and repairs," Progress in Struct ural Engineering and Materials, vol. 4, pp. 149-160, 2002.

[7] F. Wegian and H. Abdalla, "Shear capacity of concrete beams reinforced with fiber reinforced polymers," Composite Structures, vol. 71, pp. 130-138, 2005.

[8] Li Baolei,SongLi,FAN Cheng and Wang Jiaxiang, "Finite Element Analysis of the bending performance influencing of FRP Reinforced Concrete Beams," Journal of Water Resources and Architectural Engineering, pp. 100-104,115, 2015. [in chinese]

[9] V. Gribniak, G. Kaklauskas, D. Cygas, D. Bacinskas, R. Kupliauskas, and A. Sokolov, "Investigation of concrete cracking effect in deck slab of continuous bridges," The Baltic Journal of Road and Bridge Engineering, vol. 5, pp. 83-88, 2010.

[10] Lu Xilin, Jin Guofang and Wu Xiaohan, Nonlinear Finite Element of Reinforced Concrete StructuresTheory and Application vol. 6: Tongji University publishing house, 1997. [in chinese]

[11] Zhuang Zhuo, Zhang Fan, Cen Song, You xiaochuan, Yu xuguang, Mou Quanchen, et al., " Nonlinear Analysis of Reinforced Concrete Beam Bending Failure Experimental Based on ABAQUS," ed: Beijing: Science publishing house, 2005. [in chinese]

[12] D. Systèmes, "Abaqus analysis user's manual," Simulia Corp. Providence, RI, USA, 2007.

[13] X. Li, H. Lv, and S. Zhou, "Flexural behavior of GFRP-reinforced concrete encased steel composite beams," Construction and Building Materials, vol. 28, pp. 255-262, 2012.

[14] M. A. Adam, M. Said, A. A. Mahmoud, and A. S. Shanour, "Analytical and experimental flexural behavior of concrete beams reinforced with glass fiber reinforced polymers bars," Construction and Building Materials, vol. 84, pp. 354-366, 2015. 